\title{
Modelling wind erosion for Australia for prioritisation of national Landcare investments
}

\author{
$\underline{\text { J. Leys }}^{\text {a }}$, A. Chappell ${ }^{\text {}}$, J. Mewett ${ }^{\mathrm{c}}$ and M. Barson ${ }^{\mathrm{d}}$ \\ ${ }^{a}$ Knowledge Services Team, Science Division, NSW Environment and Heritage, Gunnedah NSW \\ ${ }^{b}$ Injekta Field Systems, Kent Town South Australia \\ ${ }^{c}$ Australian Bureau of Agricultural and Resource Economics and Sciences, Braddon ACT \\ ${ }^{d}$ Sustainable Agriculture, Fisheries and Forestry Division, Department of Agriculture and Water Resources, \\ Civic ACT \\ Email:john.leys@environment.nsw.gov.au
}

\begin{abstract}
Soil underpins Australia's agricultural production, biodiversity and provides ecosystem services that benefit the entire community. Wind erosion threatens the soil asset through its removal of soil and nutrients and its redistribution across the landscape. Wind erosion also threatens air and water quality. Therefore, the management of ground cover by farmers and graziers is critical to the provision of ecosystem services and ecosystem and agricultural productivity. The National Landcare program Phase 2 is to continue investment in natural resource management. Funds will be targeted to those areas where the need is greatest to protect and enhance Australia's natural resources.
\end{abstract}

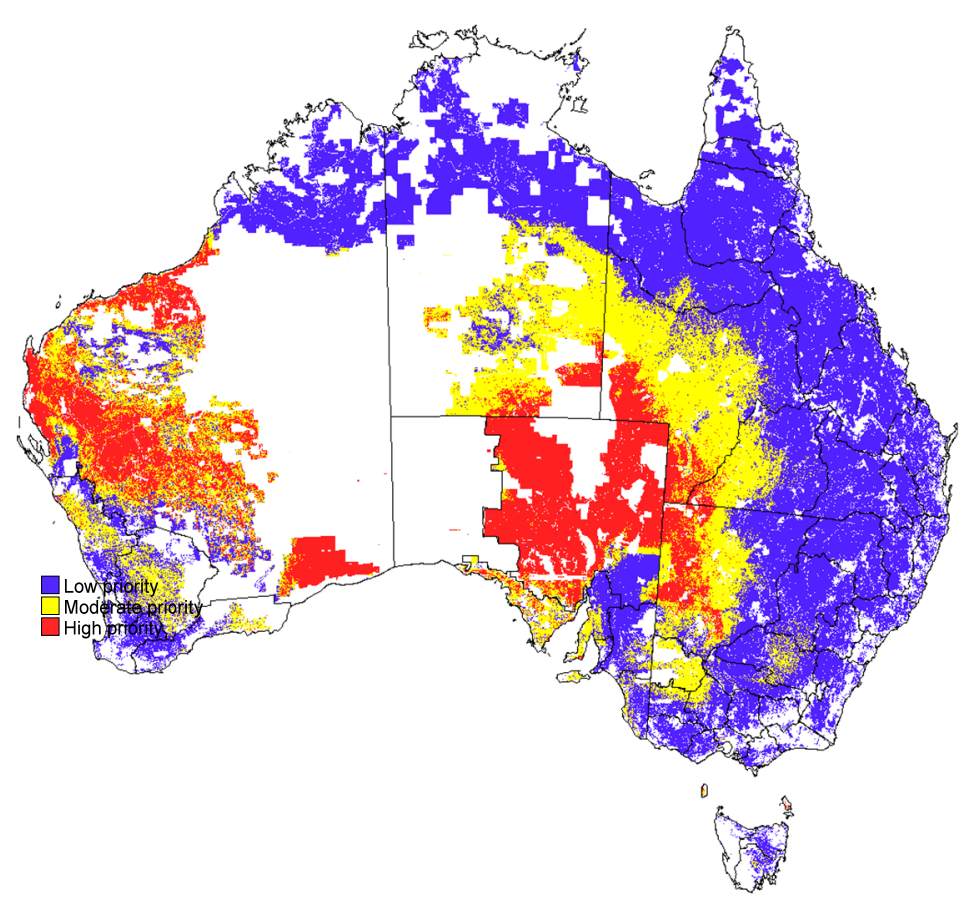

Figure 1. Priority areas for investment to reduce soil loss through control wind erosion on agricultural land. Boundaries for states and territories and natural resource management regions shown, White $=$ non-agricultural land
The purpose of this study is to produce advice for the National Landcare Program to identify where funding of improvements in ground cover management on agricultural lands will give the best returns on investment (Figure 1). The process was to use the Multi-Criteria Analysis Shell for Spatial Decision Support (MCAS-S) to combine three principal layers to form a priority map for investment. The three layers were: 1) A new modelled map of wind erosion severity for the period 2000-2010, 2) An index map of the total soil fertility loss derived from The Soil and Landscape Grid of Australia, and 3) Two maps of "room for improvement in land management practices" for cropping and grazing lands sourced from the 2012 Agricultural Resource Management Survey data.

This project improves on the 2012 Caring for Our Country prioritisation process by using a more physically based model and enabling finer scale mapping that show more landscape features. When combined with the land management improvement data this also helps weight investment to regions with lower levels of desirable management practices.

Keywords: Modelling, wind erosion, multi-criteria analysis 


\section{INTRODUCTION}

Soils are integral to Australian ecosystems for the maintenance of biodiversity and agricultural production and the provision of ecosystem services like clean air and water (Jónsson and Davíðsdóttir 2016). Land managers make decisions every day that can either help control or exacerbate wind erosion. The National Landcare program Phase 2 is to continue investment in natural resource management with aim of protected Australia's natural resources though the implementation of better land management practices. However, funds are limited and need to be targeted to where the need is greatest. will be targeted to those areas where the need is greatest to protect and enhance Australia's natural resources.

Wind erosion is a threat to the soil (Leys et al. 2011) and air quality (Chan et al. 2004) of Australia. Soils degraded by wind erosion have diminished soil nutrients that underpin terrestrial plant production (Webb et al. 2012). Eroded dust travels thousands of kilometres (O'Loingsigh et al. 2017) and can cause economic losses of greater than $\$ 300 \mathrm{M}$ (Tozer and Leys 2013). Therefore, the maintenance of ground cover is critical to ecosystem and agricultural productivity. Ground cover is defined as the ground surface sheltered by upstream obstacles, such as dead and live vegetation, rock or surface roughness like soil clods (Figure 2). The sheltered area is dependent on wind speed. The faster the wind the smaller the sheltered area.

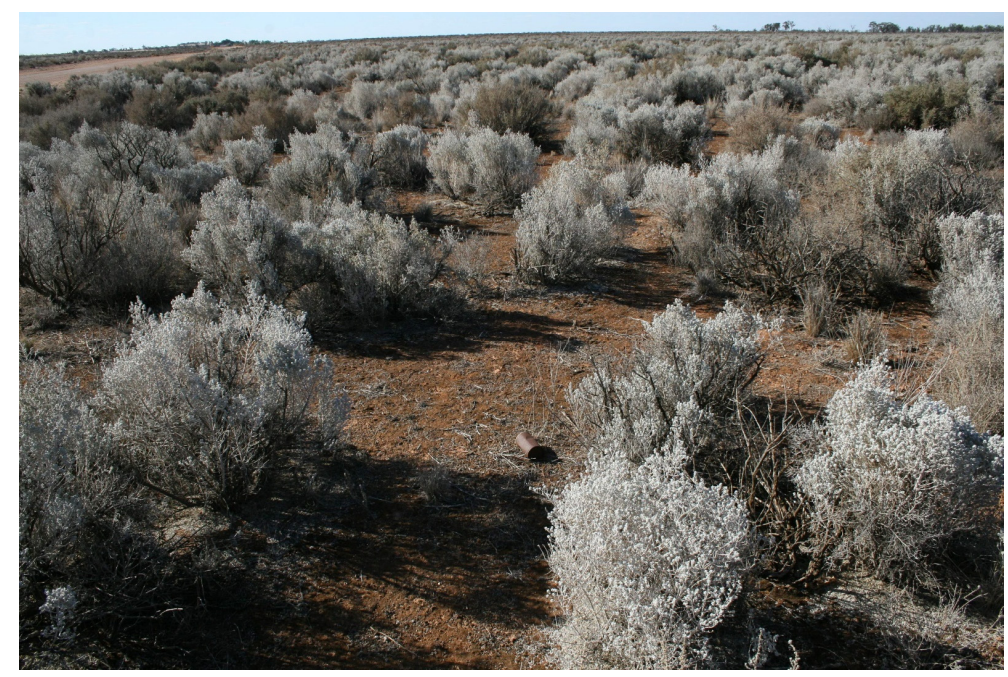

Figure 2. Ground cover is the area sheltered from wind erosion. In this photo, it is the area occupied by the vegetation, both dead and live, plus the sheltered area as represented by shadow.

When the surface soil is dry and unprotected, strong winds can mobilize particles on the surface which bombard the exposed soil surface causing fines, rich in soil organic carbon (SOC) and nutrients, to be removed in dust. The consequent loss of dust reduces the soil's ability to withstand subsequent wind erosion by reducing its moisture holding capacity, its soil aggregate stability and the soil fertility which promotes vegetation growth.

If the ecosystem services of soils are to be maintained, then it is critical that we reduce the erosion threat to soils. To do this we need to model the wind erosion at landscape scales. This study applies a new albedo wind erosion model proposed by Chappell and Webb (2016). Being able to model at the $500 \mathrm{~m}$ spatial resolution and updating the surface roughness every eight days provides increased information for decision making.

Land managers are the key to protecting our soils. Land managers who aim to maintain ground cover above the level required to control erosion; that is $50 \%$ of the surface covered in plants, obstacles and shadow (Leys 1999) as shown in Figure 2, are protecting their own soil assets and the air quality for the broader community. Areas where ground cover is not well managed may require investment to improve land management practices.

The purpose of this study is to produce advice for the National Landcare Program to identify where funding of improvements in ground cover management on agricultural lands will give the best returns on investment.

\section{METHODS}

\subsection{Overview}

There were several steps in the production of the final the priority investment map as outlined in Figure 1. 
1. To produce a map of where the soil asset, as represented by the soil fertility, is most under threat from wind erosion

2. To produce a map of where there was room for improvement in ground cover land management practices of farmers and graziers

3. Combine 1 and 2 above to produce the priority investment map using the multi-criteria analysis software MCAS-S.

\subsection{New "albedo" wind erosion model}

One of the most influential approximations in wind erosion modelling is that momentum extracted by roughness elements can be represented by roughness density (lateral cover $L$ or the frontal area index; (Wooding et al. 1973)). The $L$ underpins current wind erosion models. Chappell and Webb (2016) revealed a fundamental weakness in $L$ and demonstrated that, using current modelling methods, values of $L$ are an order of magnitude too small. Significant aerodynamic interactions between roughness elements and their sheltered areas are also omitted, particularly under sparse surface roughness $(0.001<L<0.1)$ such as in the dry years in the rangelands of central Australia or in over-cultivated bare cropping paddocks.

Chappell and Webb (2016) returned to the fundamental approximation of aerodynamic roughness; that the ground surface is sheltered by upstream obstacles, and the size of the sheltered area is dependent on wind speed (Figure 3). They developed a new approach to wind erosion modelling which replaced $L$ with a relationship between sheltered area and the proportion of shadow over a given area (Chappell et al. 2010).
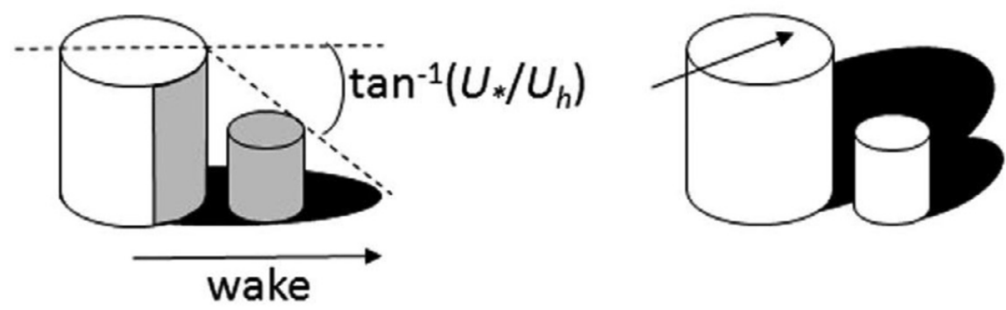

Figure 3. The (a) Raupach (1992) concept for reducing the complexity of aerodynamic roughness and its representation (b) using shadow by Chappell et al. (2010) to enable using remote sensing.

The new approach demonstrated redundancy in aerodynamic properties which were replaced with shadow calibrated against a previous wind tunnel study. The horizontal sediment flux $\left(Q_{h}\right)$ equation remains similar in form to the previous model, but is considerably reduced in complexity and uncertainty:

$\mathbf{Q}_{\mathbf{h}}\left(\mathbf{U}_{\mathbf{f}}, \mathbf{D}, \boldsymbol{\omega}_{\mathrm{ns}}, \mathbf{w}\right)=\mathbf{c}_{\text {shao }} \frac{\rho_{\mathbf{a}} \mathbf{u}_{\mathbf{S} *}^{3}}{\mathrm{~g}}\left(1-\left(\frac{\mathbf{u}_{* \mathrm{ts}} \mathbf{H}(\mathbf{w})}{\mathbf{u}_{\mathbf{S} *}}\right)^{2}\right)$

where constants include $c_{\text {shao }}$ a tuning factor which changes the magnitude, $\rho_{a}$ is the air density $\left(1.23 \mathrm{~kg} \mathrm{~m}^{-3}\right)$, $g$ is acceleration due to gravity $\left(9.81 \mathrm{~m} \mathrm{~s}^{-1}\right)$ and the bare soil threshold friction velocity $(u * t s)$

$\mathbf{u}_{* \mathrm{ts}}(\mathbf{D})=\left(\mathbf{A}_{\mathbf{N}}\left(\frac{\rho_{\mathrm{p}} \mathrm{gD}}{\rho_{\mathrm{a}}}+\frac{\Gamma}{\rho_{\mathrm{a}} \mathrm{D}}\right)\right)^{-0.5}$

of a particle size fraction $D(63 \mu \mathrm{m})$ includes $A_{N}$ a scaling coefficient $(0.0123), \rho_{p}$ is the particle density $(2650$ $\left.\mathrm{kg} \mathrm{m}^{3}\right), g$ acceleration due to gravity $\left(9.81 \mathrm{~m} \mathrm{~s}^{-1}\right), \Gamma$ is a parameter accounting for the cohesive force $(1.65 \mathrm{x}$ $\left.10^{-4} \mathrm{~kg} \mathrm{~s}^{-2}\right)$. Variables used in $Q_{h}$ include the estimation of the shear stress at the soil surface $\left(u_{S^{*}}\right)$

$\frac{\mathrm{u}_{\mathrm{S} *}}{\mathrm{U}_{\mathrm{f}}}=0.0311\left(\frac{\mathrm{e}^{-\omega_{\mathrm{ns}} \mathrm{s}^{1.131}}}{0.016}\right)+0.007$

using $10 \mathrm{~m}$ wind speed $\left(U_{f}\right)$ and the direct beam directional hemispherical reflectance (or black sky albedo $\omega$ ) inverted to reveal the shadow (1- $\omega)$ and normalised by the black sky albedo of the surface when illuminated and viewed at nadir $\left(\omega_{n}=(1-\omega) / \omega_{0}\right)$. The normalised albedo $\left(\omega_{n}\right)$ is then rescaled $\left(\omega_{n s}\right)$ from the normalised range $\left(\omega_{n \min }, \omega_{n \max }\right.$ of a given waveband $\left.v\right)$ using the following equation:

$\omega_{\mathrm{ns}}=\frac{\left(\omega-\omega_{\min }\right)}{\left(\omega_{\max }-\omega_{\min }\right)}$. 
The function $H$ (dimensionless) proposed by Shao (1997) is used to adjust $Q_{h}$ according to the volumetric soil moisture content $w\left(\mathrm{~m}^{3} \mathrm{~m}^{-3}\right)$.

$$
\begin{aligned}
& H(w)=e^{22.7 w} w \leq 0.03 . \\
& H(w)=e^{95.3 w-2.029} w>0.03 .
\end{aligned}
$$

The timescale of this function is based on soil moisture experiments in a wind tunnel which are assumed to be constant over the duration of the experiment. Since the soil moisture data which will be used in the analysis is three-hourly, it is likely that the timescale of the function will need to be adjusted. We modified the threshold of the function and adjusted its form accordingly:

$$
\begin{aligned}
& H(w)=e^{22.7 w} w \leq 0.015 . \\
& H(w)=e^{70 w-0.693} w>0.015 .
\end{aligned}
$$

\subsection{Multi-criteria shell MCAS-S}

This project combines, in a transparent way, a variety of spatial data sets. The Multi-Criteria Analysis Shell for Spatial Decision Support (MCAS-S) (ABARES 2017), is available for free from http://www.agriculture.gov.au/abares/aclump/multi-criteria-analysis. MCAS-S is a decision support program that enables the user to use raster spatial data to quickly and simply:

- $\quad$ view and classify map layers

- $\quad$ adapt and combine map layers, and

- $\quad$ produce statistical reports.

\subsection{Nutrient loss calculation}

This section outlines how a nutrient loss from wind erosion was calculated. The logic is that the soil has a nutrient store (predominantly in the topsoil) and that wind erosion is degrading that store with every wind erosion event. We acknowledge that nutrients can be replaced or created; however, we only consider loss.

The soil asset value is represented by the nutrient stock of the soil because it is the soil nutrients that underpin agricultural and ecosystem productivity of the soil. In this study, we only consider three nutrients. To calculate the "stock" of nutrient, we used the soil nutrient data from The Soil and Landscape Grid of Australia (SLGA) (CSIRO 2017) for total nitrogen (mass fraction of total nitrogen in the soil by weight $\%$ - N), total phosphorus (mass fraction of total phosphorus in the soil by weight \% - P) and organic carbon (mass fraction of carbon by weight in the $<2 \mathrm{~mm}$ soil material as determined by dry combustion at 900 Celsius \% - SOC).

The total mass in $\mathrm{t} \mathrm{ha}^{-1}$ of each nutrient $(\mathrm{N}, \mathrm{P}, \mathrm{SOC})$ in the soil profile was calculated depending on the depth of the soil in the grid cell, and in the top $5 \mathrm{~cm}$. The use of the $5 \mathrm{~cm}$ depth is likely to result in an underestimate of the nutrient loss rate, as the nutrient concentration at the very surface of the soil is higher than the average of 0 to $5 \mathrm{~cm}$. We have set the enrichment ratio to 1 . We have done this because we are using the horizontal mass flux $Q_{h}$ which includes all particle-sizes leaving the pixel. Previous work by Chappell et al. (2013) showed that wind eroded dust (sediment $<22 \mu \mathrm{m}$ ) had enrichment ratios of around 2.

To calculate nutrient loss, we need to convert the total horizontal sediment flux $Q_{h}\left(\mathrm{~g} \mathrm{~m}^{-1} \mathrm{~s}^{-1}\right)$ from $2000-2010$ to an erosion rate $(E)$ in $\mathrm{tha}^{-1} \mathrm{y}^{-1}$.

$E=Q_{h} \frac{1000000 \mathrm{~g}}{10000 \mathrm{~m}^{2}} *$

Next, we calculated the nutrient loss for each MODIS $500 \mathrm{~m}$ pixel.

$N_{l}=E * N_{5}$

Where

$N_{l}=$ loss of total nutrient in $\mathrm{t} \mathrm{ha}^{-1}$ of the nutrient type

$E=$ erosion rate in $\mathrm{tha}^{-1} \mathrm{y}^{-1}$.

$N_{5}=$ nutrient in $0-5 \mathrm{~cm}$ estimated value from the Soil and Landscape Grid of Australia in \%

Nutrients are lost from the soil at different rates, and soils have different stocks of nutrients. To enable the losses of the three nutrients used in this study to be combined into a single estimate, we calculate the relative rate of nutrient loss for each of the three nutrients by 
Leys et al., Modelling wind erosion for Australia for prioritisation of national Landcare investments

The relative rate of nutrient loss $=\frac{\text { Mean annual rate of nutrient loss per unit area }}{\text { Total soil nutrient stock per unit area }}$

Where

The total nutrient stock per unit area $=\sum_{i=1}^{I}$ (nutrient concentration in layer $i *$ the depth of layer $i$ )

An index of nutrient loss for wind erosion is calculated by combining the value of the relative rate of nutrient loss for the different types of nutrients. The simplest approach to this combination is to average the values, so:

The nutrient loss index $=\sum_{j=1}^{J}\left(\frac{\text { the relative nutrient loss rate of nutrient } j}{J}\right)$

where $\mathrm{J}$ is the number of types of nutrient considered, that is, three in this study: $\mathrm{N}, \mathrm{P}$ and SOC.

\section{RESULTS AND DISCUSSION}

\subsection{Modelled wind erosion severity map}

The new albedo-based model of horizontal sediment flux $\left(Q_{h}\right)$ was applied across Australia from February 2000 to December 2010. The 3-hourly wind and soil moisture data was aggregated to every 8 days using the maximum value and the median value, respectively. The eight-daily estimates of $Q_{h}$ were aggregated for the first 6 years of the period (2000-2005) and then the subsequent 5 years (2006-2010) to produce two summary maps of mean $Q_{h}$. The average of the two periods was used to produce the sum of $Q_{h}$ for the period 2000-2010 ().

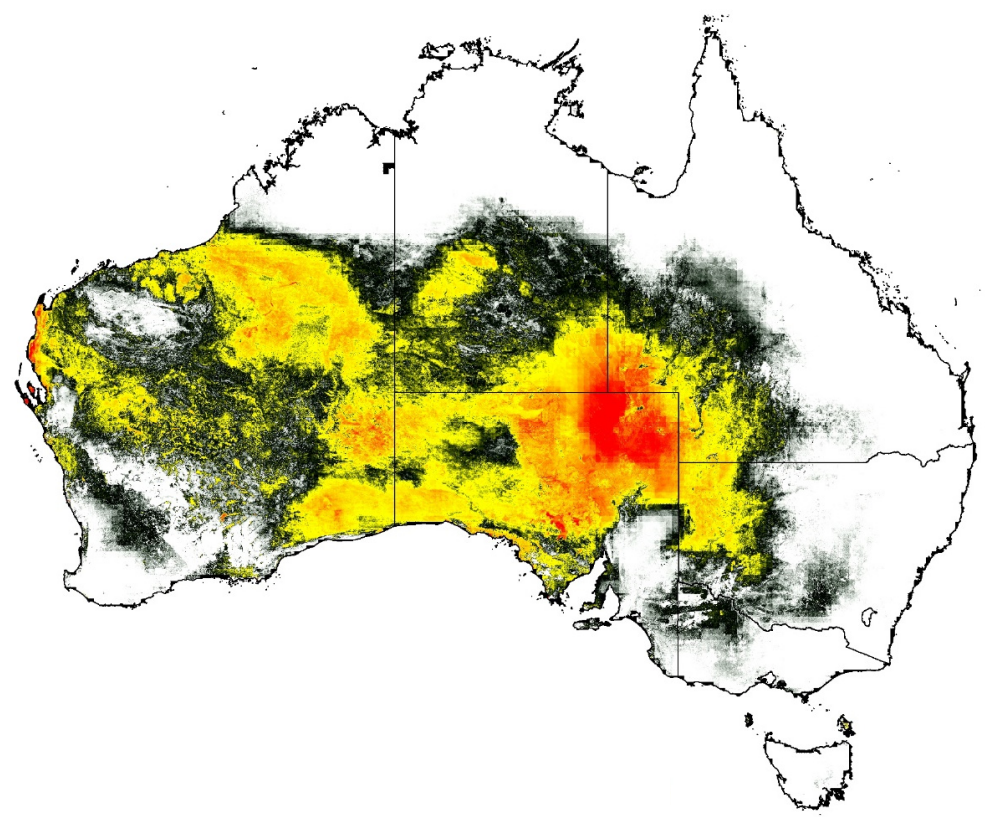

Figure 4. Total horizontal sediment flux (Qh) for 2000-2010 is estimated using the new albedo-based model. Total Qh with classes of small $<0.001 \mathrm{~g} \mathrm{~m}-1$ (black), $0.001 \leq$ medium $<0.005 \mathrm{~g} \mathrm{~m}-1$ (yellow) and large $>0.005 \mathrm{~g} \mathrm{~m}-1$ (red). SOC. The nutrient loss map is new way of looking at the impact of erosion on the soil asset by representing the loss of nutrients as a fraction of the total stock of nutrients in the soil. This indicates the significance of the nutrient loss on the soil asset.

\subsection{Priority areas for investment}

In this section, the priority areas for investment are presented. We combine the nutrient loss index for each land use; that is, cropping and grazing, with a map of where there is room for improvement in land management practices to maintain soil cover in cropping and grazing agricultural areas (Figure 5). 


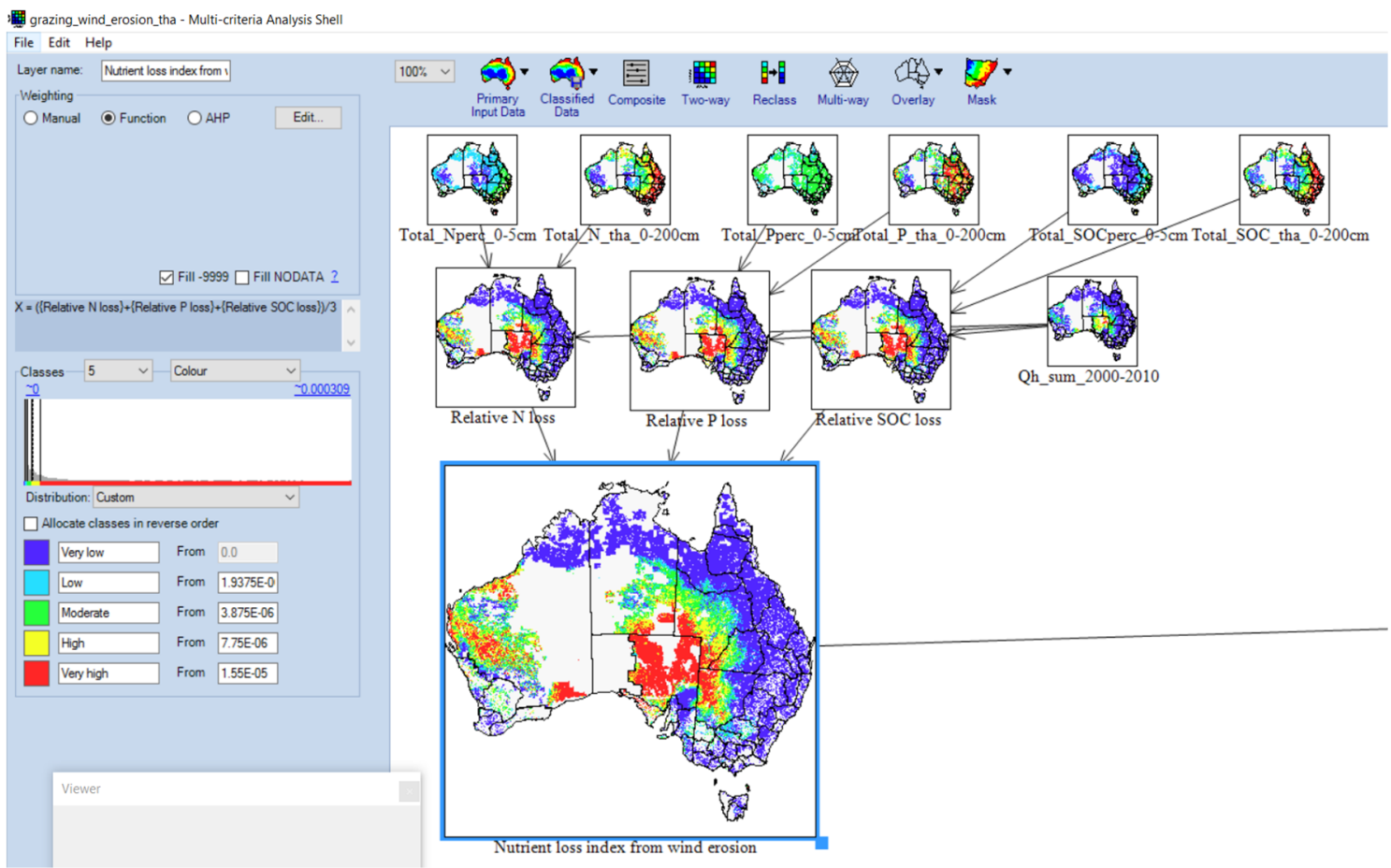

Figure 5. MCAS-S analysis for the calculation of the index of nutrient loss on grazing lands for Australia

To identify Natural Resource Management (NRM) regions that have scope for improvement in land management practices to promote ground cover, we analysed Agricultural Resource Management Survey (ARMS) data collected in 2008, 20010, 2011 and 2012. Here we used the 2012 data as it was the most recent and representative of latest farmer and grazier attitudes (ABARES 2016).

We considered four ARMS outputs, of which we selected two. For cropping lands, we selected "crop and pasture residue area left intact" as the indicator of room for improvement because farmers who are reporting leaving crop and pasture intact are demonstrating they are maintaining cover. We set a threshold for NRMs that have $<75 \%$ as those we invest in. For grazing lands, we selected "graziers with a minimum ground cover target" as the indicator of room for improvement because graziers who have a target would logically also monitor for that target level, thus managing their land to leave pasture for the maintenance of cover. The percentage of landholders with a cover target in the NRMs is rather low at $47 \%$. Thus, we set a threshold for NRMs that have $<25 \%$ should be those we invest in.

The nutrient loss index from wind erosion and the room for improvement, cropping and grazing layers were then combined to create the following cropping (Figure 6a) and grazing classes (Figure 6b). Combining the nutrient loss index with the indicator of room for improvement for each cropping and grazing resulted in the priority areas for investment areas for cropping and grazing areas (red and yellow in Figure 6). The thresholds in Figure 6 were determined by an expert panel comprised of members from the National Committee of Soil and Terrain and State agency staff. These two maps were then combined to give Figure 1. The new priority map for investment to control wind erosion is an improvement over the previous 2012 Caring for our Country priority investment map that only used erosion severity at $50 \mathrm{~km}$ resolution. The new map has finer resolution and includes the "room for improvement in land management practices" that reduce investment in areas that are already using improved management practices.

The inclusion of nutrient loss means we are assessing the loss of the nutrients from the total store of nutrients for every pixel; this is a measure of the decline in the economic production from the soil asset. The effect of this is to reveal not only those areas with high erosion, but also those areas with low erosion that is having a large impact on the soil nutrient store. For example, the eastern Riverina in NSW has a high nutrient loss even though the erosion levels are low and the need for improvement in the Local Land Services Region Riverina is high. 
a)
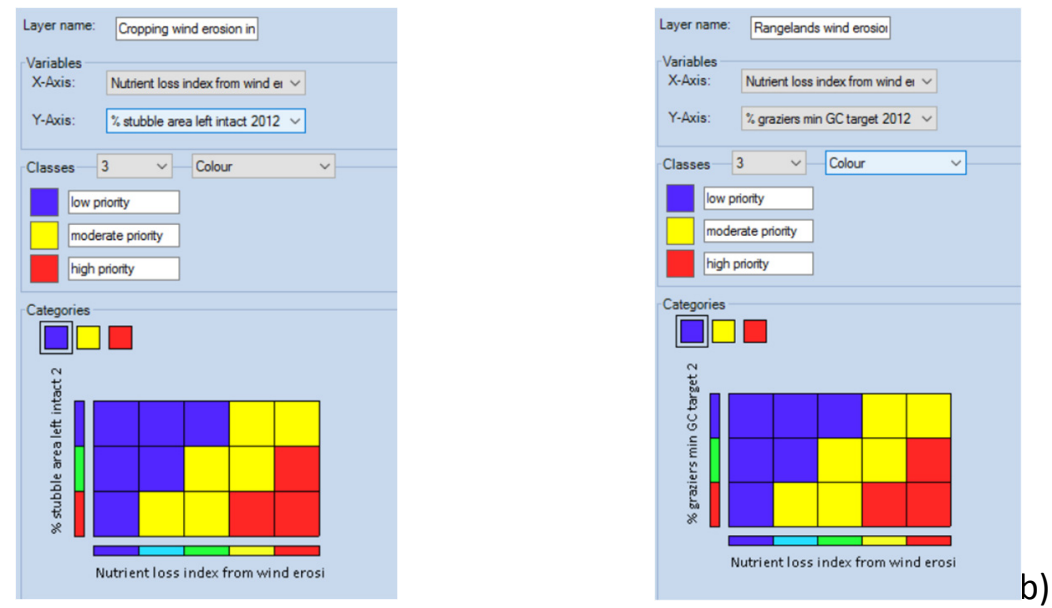

Figure 6. Matrix for priority areas for investment areas for a) cropping and b) grazing

\section{CONCLUSIONS}

This project has produced advice for the National Landcare Program to identify where funding of improvements in ground cover management agricultural lands will give the best returns on investment. This is critical as resources are limited and encouraging practice change in areas that have high nutrient loss and dust production is the goal of the National Landcare program. The public investment will protect the production values of the soils and provide ecosystem services of clean air to the wider community.

Improvements since the 2012 investment map included: higher resolution wind erosion mapping with an improved model, mapping proportion of soil nutrient loss from the total soil nutrient stock, and identification of NRMs with room for improvement in land management practices that maintain soil cover.

\section{REFERENCES}

ABARES (2016). Land use of Australia 2010-11 ABARES, Canberra, Date Accessed: 23 July 2017, http://data.daff.gov.au/anrdl/metadata files/pb_luav5g9abll20160704.xml.

ABARES (2017). Multi-criteria analysis (MCAS-S). Department of Agriculture and Water Resouces ABARES, Canberra, Date Accessed: 20 July 2017 , http://www.agriculture.gov.au/abares/aclump/multi-criteria-analysis.

Butler HJ, Shao Y, Leys JF, McTainsh GH (2007). Modelling wind erosion at national \& regional scale using the CEMSYS model. National Land \& Water Resources Audit, Canberra.

Chappell A, Webb NP (2016). Using albedo to reform wind erosion modelling, mapping and monitoring. Aeolian Research 23, 63-78. doi: http://dx.doi.org/10.1016/j.aeolia.2016.09.006.

Chappell A, Dong Z, Zobeck T, Van Pelt S (2010). Estimating aerodynamic resistance of rough surfaces using angular reflectance. Remote Sensing of Environment 114 (7), 1462-1470. doi: 10.1016/j.rse.2010.01.025.

CSIRO (2017). Soil and Landscape Grid of Australia. CSIRO, Canberra, Date Accessed: 20 July 2017, http://www.clw.csiro.au/aclep/soilandlandscapegrid/.

Jónsson JÖG, Davíosdóttir B (2016). Classification and valuation of soil ecosystem services. Agricultural Systems 145, 24-38. doi: http://dx.doi.org/10.1016/j.agsy.2016.02.010.

Leys JF (1999). Wind erosion on agricultural land. In 'Aeolian Environments, Sediments and Landforms.' (Eds AS Goudie, I Livingston and S Stokes) pp. 143-166. (John Wiley and Sons: England)

O'Loingsigh T, Chubb T, Baddock M, Kelly T, Tapper NJ, De Deckker P, McTainsh G (2017). Sources and pathways of dust during the Australian "Millennium Drought" decade. Journal of Geophysical Research: Atmospheres. doi: 10.1002/2016JD025737.

Shao Y (1997). Soil moisture prediction of the Australian continent. Meteorological Atmospheric Phyisics 63, 195-215.

Tozer P, Leys J (2013). Dust storms: What do they really cost? The Rangeland Journal 35, 131-142. doi: 10.1071/RJ12085.

Wooding RA, Bradley EF, Marshall JK (1973). Drag due to regular arrays of roughness elements of varying geometry. Boundary-Layer Meteorology 5, 285-308. 